\title{
Assessment of Pulmonary Artery Pressure in Chronic Obstructive Pulmonary Disease Patients without Resting Hypoxemia
}

\author{
Muhammed Ali Mahmoud Farrag ${ }^{1}$, Mohamed Ali ElSayed ${ }^{1}$, Ahmed Mohamed El \\ Mahmoudy $^{2}$, Alaa Gamal Youssef El Mashad ${ }^{1}$ \\ ${ }^{1}$ Department of Chest Diseases, and ${ }^{2}$ Department of Cardiology, Faculty of Medicine, Ain \\ Shams University, Cairo, Egypt \\ Corresponding author: Alaa Gamal Youssef El Mashad, Mobile: 01069999290; Email: \\ alaaelmashad@hotmail.com
}

\begin{abstract}
Background: Chronic obstructive pulmonary disease (COPD) is a disease state characterized by progressive airflow limitation and is associated with an abnormal inflammatory response of the lungs to noxious particles or gases, primarily caused by cigarette smoking. Pulmonary hypertension primarily occurs in COPD patients with severe hypoxemia and fortunately it is typically mild. Hypoxemia increases pulmonary artery pressure (PAP) through hypoxic pulmonary vasoconstriction and vascular remodeling, but there is a correlation between lung function parameters and PAP, suggesting that factors other than airway obstruction and/or loss of alveolar surface may play a role in its etiology.
\end{abstract}

Objective: The aim of the work was to Identify other factors other than resting hypoxemia contributing to pulmonary hypertension in COPD patients.

Patients and Methods: This study was a prospective study including 80 cases referred to Ain Shams University Hospitals presented with COPD defined using the standard criteria for chronic bronchitis. All patients underwent spirometry with pre and post bronchodilator treatment and trans-thoracic echocardiography.

Results: The results showed that there was significant correlation between right ventricular systolic pressure (RVSP) values and each of the following; age, duration of smoking and degree of airway obstruction which were all contributing to pulmonary hypertension in COPD patients. Among 80 patients, 18 had elevated RVSP value. The mean age of those 18 patients was $58.8 \pm 7.78$ years while in those with normal RVSP $54.15 \pm 10.56$ years. Those 18 patients had mean FEV1 percentage of predicted $44.5 \pm 12.1 \%$ while in those with normal RVSP value $48.72 \pm 1.62 \%$. Among those 18 patients 16 had history of smoking for $>20$ years representing $88.9 \%$. Multivariate analysis showed that among all the studied parameters in our study, degree of obstruction determined by measured FEV1 percentage of predicted is an independent predictor for pulmonary hypertension in stable COPD patients.

Conclusion: It could be concluded that pulmonary hypertension occurs frequently in stable COPD outpatients without resting hypoxemia and that age, duration of smoking and low prebronchodilator FEV1 are all risk factors for pulmonary hypertension. And that degree of airway obstruction is an independent predictor for pulmonary hypertension in stable COPD patients.

Keywords: Pulmonary arterial hypertension, Forced expiratory volume in the first second, Right ventricular systolic pressure

\section{INTRODUCTION}

Chronic obstructive pulmonary disease (COPD) is a disease state characterized by progressive airflow limitation and is associated with an abnormal inflammatory response of the lungs to noxious particles or gases, primarily caused by cigarette smoking ${ }^{(1)}$. 
The development of pulmonary hypertension is often observed in advanced chronic obstructive pulmonary disease (COPD) and indicates a poor prognosis, with a 5-year survival rate of $20-36 \%^{(2)}$.

Pulmonary hypertension primarily occurs in COPD patients with severe hypoxemia and fortunately it is typically mild. Hypoxemia increases pulmonary artery pressure (PAP) through hypoxic pulmonary vasoconstriction and vascular remodeling, but there is a poor correlation between lung function parameters and PAP, suggesting that factors other than airway obstruction and/or loss of alveolar surface may play a role in its etiology ${ }^{(3)}$.

Some studies have shown that a proportion of patients with only moderate airway obstruction have severe pulmonary hypertension. Disproportionate pulmonary hypertension in COPD patients seems best defined as at least moderate elevation in the mean PAP despite only mild to moderate reductions in forced expiratory volume in 1 second (FEV1) $(>50 \%$ predicted) ${ }^{(4)}$.

In COPD patients, inflammation most likely involving IL-6 contributes in occurrence of pulmonary hypertension complicating $\mathrm{COPD}^{(5)}$.

The aim of the work was to assess pulmonary artery pressure in chronic obstructive pulmonary disease patients without resting hypoxemia to identify other factors other than resting hypoxemia contributing to pulmonary hypertension in those patients.

\section{PATIENTS AND METHODS}

This prospective study included a total of 80 cases attending at Ain Shams University Hospitals, who presented with COPD defined using the standard criteria for chronic bronchitis, i.e. presence of cough with expectoration for more than three months in a year for the past two or more years with history of exposure to a predisposing factor (e.g. smoking). Approval of the ethical committee and a written informed consent from all the subjects were obtained. This study was conducted between December 2017 and July 2018.

Inclusion criteria: Patients with chronic obstructive lung disease without resting hypoxemia with FEV1/FVC $<70 \%$, blood oxygen saturation ( $\mathrm{SpO} 2)$ by pulse oximetry at room air $>95 \%$.

Patients having one or more of the following criteria are excluded from the study: Hypoxic patients (SpO2 $<95 \%$ ). Patients with clinically apparent or known cardiovascular disease. Patients with history of previous pulmonary embolism. Patients with connective tissue disease. Patients with other systemic illness causing pulmonary hypertension.

All patients are subjected to the following: Personal and medical history including age, gender, smoking habits, associated co-morbidities. Vital data (Blood pressure, heart rate, respiratory rate, BMI). Laboratory investigations including Arterial blood gases on room air, complete blood count, kidney function tests, liver function tests, and Spirometry.

\section{RESULTS}

Table (1): Baseline demographic \& clinical data

\begin{tabular}{|l|l|c|}
\hline \multicolumn{2}{|l|}{} & No. $=\mathbf{8 0}$ \\
\hline \multirow{2}{*}{ Age } & Mean \pm SD & $57.69 \pm 9.16$ \\
Range & $32-77$ \\
\hline
\end{tabular}


Table (2): Duration of Smoking.

\begin{tabular}{|l|l|c|c|}
\hline \multicolumn{2}{|c|}{} & No. & \% \\
\hline \multirow{2}{*}{ Duration of Smoking } & $<20$ years & 24 & $30.0 \%$ \\
& $>20$ years & 56 & $70.0 \%$ \\
\hline
\end{tabular}

Table (3): Grade of Spirometry and resting $\mathrm{O}_{2}$ saturation

\begin{tabular}{|c|c|c|c|}
\hline & & \multicolumn{2}{|c|}{ No. $=80$} \\
\hline \multirow{2}{*}{ FEV1 (\%) } & Mean \pm SD & \multicolumn{2}{|c|}{$47.79 \pm 12.68$} \\
\hline & Range & \multicolumn{2}{|c|}{$25-76$} \\
\hline \multirow{3}{*}{$\mathrm{Sp} \mathrm{O}_{2}(\%)$} & Mean \pm SD & \multicolumn{2}{|c|}{$95.8 \pm 0.72$} \\
\hline & Range & \multicolumn{2}{|c|}{$95-97$} \\
\hline & & No. & $\%$ \\
\hline \multirow{5}{*}{ Grade of severity } & Mild obstructive & 5 & $6.3 \%$ \\
\hline & Moderate obstructive & 15 & $18.7 \%$ \\
\hline & Moderately severe obstructive & 19 & $23.8 \%$ \\
\hline & Severe obstructive & 15 & $18.7 \%$ \\
\hline & Very severe obstructive & 26 & $32.5 \%$ \\
\hline
\end{tabular}

Table (4): RVSP value, estimated RAP and TR velocity

\begin{tabular}{|l|l|l|}
\hline \multicolumn{2}{|l|}{} & No. $=\mathbf{8 0}$ \\
\hline \multirow{2}{*}{ RVSP(mmHg) } & Mean \pm SD & $25.91 \pm 11.44$ \\
\cline { 2 - 3 } & Range & $16-57$ \\
\hline \multirow{2}{*}{ RAP(mmHg) } & Mean \pm SD & $5.81 \pm 1.86$ \\
\cline { 2 - 3 } & Range & $5-10$ \\
\hline \multirow{2}{*}{ TRv $(\mathrm{m} / \mathrm{s})$} & Mean \pm SD & $2.17 \pm 0.48$ \\
\cline { 2 - 3 } & Range & $1.6-3.35$ \\
\hline \multirow{2}{*}{ TRv value } & Normal & $67(83.8 \%)$ \\
\cline { 2 - 3 } & Elevated & $13(16.2 \%)$ \\
\hline \multirow{2}{*}{ RVSP value } & Normal & $62(77.5 \%)$ \\
\cline { 2 - 3 } & Elevated & $18(22.5 \%)$ \\
\hline
\end{tabular}

Table (5): Hemoglobin value data

\begin{tabular}{|l|l|l|}
\hline \multicolumn{2}{|c|}{} & No. $=\mathbf{8 0}$ \\
\hline \multirow{2}{*}{ Hb concentration $(\mathrm{g} / \mathrm{dl})$} & Mean \pm SD & $13.83 \pm 1.57$ \\
& Range & $10.2-17$ \\
\hline
\end{tabular}

Table (6): Correlation between demographic data and RVSP value

\begin{tabular}{|c|c|c|c|c|c|c|}
\hline & & \multicolumn{2}{|c|}{ RVSP value } & \multirow{3}{*}{ Test value } & \multirow{3}{*}{ P-value } & \multirow{3}{*}{ Sig. } \\
\hline & & Normal & Elevated & & & \\
\hline & & No. $=62$ & No. $=18$ & & & \\
\hline Age (years) & $\begin{array}{l}\text { Mean } \pm \text { SD } \\
\text { Range }\end{array}$ & $\begin{array}{c}54.15 \pm 10.56 \\
37-73\end{array}$ & $\begin{array}{c}58.8 \pm 7.78 \\
32-77\end{array}$ & $2.052 \bullet$ & 0.044 & $\mathrm{~S}$ \\
\hline
\end{tabular}

Table (7): Correlation between RVSP value and duration of smoking

\begin{tabular}{|c|c|c|c|c|c|c|c|c|}
\hline & & \multicolumn{4}{|c|}{ RVSP value } & \multirow{3}{*}{ Test value* } & \multirow{3}{*}{ P-value } & \multirow{3}{*}{ Sig. } \\
\hline & & \multicolumn{2}{|c|}{ Normal } & \multicolumn{2}{|c|}{ Elevated } & & & \\
\hline & & No. & $\%$ & No. & $\%$ & & & \\
\hline $\begin{array}{l}\text { Duration of } \\
\text { Smoking }\end{array}$ & $\begin{array}{l}<20 \text { years } \\
>20 \text { years }\end{array}$ & $\begin{array}{l}23 \\
39\end{array}$ & $\begin{array}{l}37.1 \% \\
62.9 \%\end{array}$ & $\begin{array}{c}2 \\
16\end{array}$ & $\begin{array}{l}11.1 \% \\
88.9 \%\end{array}$ & 4.384 & 0.036 & $\mathrm{~S}$ \\
\hline
\end{tabular}


Table (8): Correlation between RVSP value, RAP, TR velocity and degree of obstruction among studied population

\begin{tabular}{|l|c|c|c|}
\hline \multirow{2}{*}{} & \multicolumn{2}{|c|}{ FEV1 (\%) } & \multirow{2}{*}{ Sig. } \\
\cline { 2 - 3 } & $\mathbf{R}$ & P-value & S \\
\hline RVSP & $-0.291^{* *}$ & 0.009 & $\mathrm{~S}$ \\
\hline RAP & $-0.221^{*}$ & 0.049 & $\mathrm{~S}$ \\
\hline
\end{tabular}

Table (9): Correlation between RVSP value and Hemoglobin level

\begin{tabular}{|c|c|c|c|c|c|c|}
\hline & & \multicolumn{2}{|c|}{ RVSP value } & \multirow{3}{*}{ Test value } & \multirow{3}{*}{ P-value } & \multirow{3}{*}{ Sig. } \\
\hline & & Normal & Elevated & & & \\
\hline & & No. $=62$ & No. $=18$ & & & \\
\hline Hb value (g/dl) & $\begin{array}{l}\text { Mean } \pm \text { SD } \\
\text { Range }\end{array}$ & $\begin{array}{c}13.65 \pm 1.59 \\
10.2-17\end{array}$ & $\begin{array}{c}14.46 \pm 1.34 \\
12.5-17\end{array}$ & $-1.968 \bullet$ & 0.053 & NS \\
\hline
\end{tabular}

Table (10): Multivariate linear regression analysis for predictors of RVSP level

\begin{tabular}{|l|c|c|c|c|c|}
\hline & \multicolumn{2}{|c|}{$\begin{array}{c}\text { Unstandardized } \\
\text { Coefficients }\end{array}$} & \multirow{2}{*}{$\begin{array}{c}\text { Standardized } \\
\text { Coefficients }\end{array}$} & \multirow{2}{*}{ t } & P-value \\
\cline { 2 - 5 } & B & SE & Beta & & \\
\hline Age & 0.040 & 0.151 & 0.032 & 0.263 & 0.793 \\
\hline Duration of Smoking & 2.732 & 2.992 & 0.110 & 0.913 & 0.364 \\
\hline FEV1 (\%) & -0.257 & 0.099 & -0.285 & -2.593 & 0.011 \\
\hline
\end{tabular}

Table (11): multivariate linear regression analysis for predictors of TRv level

\begin{tabular}{|l|c|c|c|c|c|}
\hline \multirow{2}{*}{} & \multicolumn{2}{|c|}{$\begin{array}{c}\text { Unstandardized } \\
\text { Coefficients }\end{array}$} & \multirow{2}{*}{$\begin{array}{c}\text { Standardized } \\
\text { Coefficients }\end{array}$} & \multirow{2}{*}{ t } & \multirow{2}{*}{ P-value } \\
\cline { 2 - 5 } & B & SE & Beta & \\
\hline Age & -0.001 & 0.006 & -0.024 & -0.194 & 0.846 \\
\hline Duration of Smoking & 0.142 & 0.126 & 0.137 & 1.126 & 0.264 \\
\hline FEV1 (\%) & -0.010 & 0.004 & -0.269 & -2.424 & 0.018 \\
\hline
\end{tabular}

\section{DISCUSSION}

Chronic Obstructive Pulmonary Disease (COPD) is a common preventable and treatable disease that is characterized by persistent respiratory symptoms and airflow limitation that is due to airway and/or alveolar abnormalities usually caused by significant exposure to noxious particles or gases. However, in many patients, the disease is associated with several systemic manifestations that can effectively result in impaired functional capacity, worsening dyspnea, reduced health related quality of life and increased mortality ${ }^{(6)}$.

Pulmonary hypertension primarily occurs in COPD patients with severe hypoxemia. Hypoxemia increases pulmonary artery pressure (PAP) through hypoxic pulmonary vasoconstriction and vascular remodeling, but there is a poor correlation between lung function parameters and PAP, suggesting that factors other than airway obstruction and/or loss of alveolar surface may play a role in its etiology ${ }^{(3)}$.

In the current study we enrolled 80 cases referred to Ain Shams University 
Hospitals presented with COPD defined using the standard criteria for chronic bronchitis, i.e. presence of cough with expectoration for more than three months in a year for the past two or more years with history of exposure to a predisposing factor (e.g. smoking) without resting hypoxemia to assess causes other than hypoxemia implicated in the etiology of pulmonary hypertension in COPD patients.

The mean age of the studied population was $57.69 \pm 9.16$ years, males were predominant comprising $92.5 \%$ of the study population.

In the current study there was significant correlation between Age and elevated RVSP value, where the mean age of patients having elevated RVSP value was $58.8 \pm 7.78$ years while in those with normal RVSP $54.15 \pm 10.56$, which is matching with the retrospective study published by Fayngersh et al. ${ }^{(7)}$ involving outpatients with COPD and pulmonary hypertension which concluded that only age and pre-bronchodilator FEV1\% predicted were independent predictors of pulmonary hypertension in their population of patients, suggesting that pulmonary hypertension in COPD is associated more with increasing age and airflow obstruction than with lung hyperinflation ${ }^{(7)}$.

In this study there was also significant correlation between duration of smoking and elevated RVSP value where $88.9 \%$ of patients with elevated RVSP value were smokers for $>20$ years while $11.1 \%$ of patients with elevated RVSP value were smokers for $<20$ years, which is matching with the study published by Wright et al. ${ }^{(8)}$ which concluded that pulmonary hypertension is probably a result of the direct effect of tobacco smoke on the intrapulmonary vessels with abnormal production of mediators that control vasoconstriction, vasodilatation, and vascular cell proliferation, ultimately leading to aberrant vascular remodelling and aberrant vascular physiology. These changes are in many ways similar to those seen in other forms of pulmonary hypertension and suggest that the treatments used for primary pulmonary hypertension may be beneficial in patients with $\mathrm{COPD}^{(8)}$.

Also in the study conducted by Wright et al. ${ }^{(8)}$ it was interesting to note that there is substantial evidence against the notion that pulmonary hypertension in COPD patients is attributable simply to hypoxia and/or destruction of the pulmonary vascular bed by emphysema, but new mechanistic data that cigarette smoke has a direct effect on the pulmonary vasculature with up-regulation of mediators that lead to vascular structural remodeling and dynamic physiological changes in vascular function was found.

In the current study there was significant correlation between degree of airway obstruction and each of the following; elevated RVSP value, RAP and TRv, with mean FEV1 (\%) of predicted in patients with elevated RVSP $44.5 \pm 12.1 \%$ while in patients with normal RVSP $48.72 \pm 1.62 \%$, previous studies examining the relationship between degree of airway obstruction and $\mathrm{PH}$ have been conflicting, for example, this study goes in agreement with the retrospective study published by Fayngersh et al. ${ }^{(7)}$ who suggested that low pre-bronchodilator FEV1 is independent risk factors for $\mathrm{PH}$.

Although it doesn't match with the community based, cohort study published by Lee et al. ${ }^{(3)}$ involving 117 COPD patients from the Korean Obstructive Lung Disease (KOLD) (mean age 67 years), which concluded that most of the patients didn't have pulmonary hypertension despite having the most severe airflow limitation (FEV1 35\% predicted) ${ }^{(3)}$.

The study also disagrees with another community based retrospective study published by Chaouat et al. involving 27 COPD patients, which concluded that obstruction was only moderate in 11 patients with severe pulmonary hypertension (median FEV1, $50 \%$ of predicted), suggesting that the 
mechanisms causing hypoxemia were perhaps different from those in most patients with $\mathrm{COPD}^{(5)}$.

It also doesn't match with Kessler

et al. ${ }^{(9)}$ which indicated that in patients with moderately severe COPD (mean FEV1 at the onset $=1.46 \pm 0.5 \mathrm{~L}$, $44.6 \pm 15.7 \%$ of the predicted value) the natural progression of the disease does not necessarily lead, with time, to pulmonary hypertension. This probably explains why pulmonary hypertension is far from being the rule, even in patients with advanced COPD.

This discrepancy may be due to the differences in the severity of COPD between cohorts.

Multivariate analysis showed that among all the studied parameters in our study, degree of obstruction determined by FEV $1 \%$ of predicted is an independent predictor for pulmonary hypertension in stable COPD patients.

In this study we noticed that mean hemoglobin $(\mathrm{Hb})$ concentration was higher in those with elevated RVSP value with a mean $\mathrm{Hb}$ concentration in the patients with elevated RVSP of $14.46 \pm 1.34 \mathrm{~g} / \mathrm{dL}$, and a mean $\mathrm{Hb}$ concentration in the patients with normal RVSP of $13.65 \pm 1.59 \mathrm{~g} / \mathrm{dL}$, however it failed to reach a value of statistical significance, which goes in agreement with Kessler et al. (9) who concluded that hypoxia and concurrent polycythemia are not major contributors to the development of pulmonary hypertension in patients with COPD and their role in the development of $\mathrm{PH}$ is probably less important and other factors may trigger the appearance of pulmonary vascular lesions. It is presently known that other factors, for example, inflammatory factors, may initiate the remodeling of the pulmonary vascular bed in patients with COPD.

These results don't match with Lee et al. in ${ }^{(3)}$ which concluded that the $\mathrm{Hb}$ concentration was the only factor independently associated with SPAP, the study also concluded that COPD patients with anemia $(\mathrm{Hb}<13 \mathrm{~g} / \mathrm{dL})$ had a higher mean sPAP than those without anemia. And that polycythaemia occurs in COPD with hypoxia and causes an increase in blood viscosity and impaired vasodilator response to acetylcholine.

These results also don't match with Schreier et al. ${ }^{(10)}$ which concluded that dramatic increases in hematocrit increase pressure and decrease flow. Despite the increased oxygen-carrying capacity of high hematocrit blood, evidence suggests that the increase in vascular resistance decreases peripheral oxygen delivery ${ }^{(10)}$.

This conflict may be explained by the fact that most of our study population had normal hemoglobin concentrations, and resting hypoxemia was absent in all of them. These two main issues could have affected the results.

In summary, in the current study there was significant correlation between RVSP value and each of the following; age, duration of smoking and degree of airway obstruction which were all contributing to pulmonary hypertension in COPD patients, while there was no significant correlation between RVSP value and hemoglobin concentration.

\section{CONCLUSION}

In summary, our study suggests that pulmonary hypertension occurs frequently in stable COPD outpatients without resting hypoxemia and that age, duration of smoking and low pre-bronchodilator FEV1 are all risk factors for pulmonary hypertension. And that degree of airway obstruction is an independent predictor for pulmonary hypertension in stable COPD patients.

Identifying pulmonary hypertension in patients with COPD is important because of its association with increased morbidity and mortality. 


\section{REFERENCES}

1. Tajti G, Gesztelyi R, Pak K, Papp C, Keki S, Szilasi ME, Zsuga J (2017): Positive correlation of airway resistance and serum asymmetric dimethylarginine level in COPD patients with systemic markers of lowgrade inflammation. International Journal of Chronic Obstructive Pulmonary Disease, 12: 873.

2. Girgis RE and Stephen CM (2007): Pulmonary hypertension associated with chronic respiratory disease. Clinics in Chest Medicine, 28 (1): 219-232.

3. Lee JH, Oh YM, Seo JB et al. (2011): Pulmonary artery pressure in chronic obstructive pulmonary disease without resting hypoxaemia. The International Journal of Tuberculosis and Lung Disease, 15(6): 830-837.

4. Oswald-Mammosser $M$, Weitzenblum E, Quoix E et al. (1995): Prognostic factors in COPD patients receiving long-term oxygen therapy: importance of pulmonary artery pressure. Chest, 107(5):11931198.

5. Chaouat A, Savale L, Chouaid $\mathrm{C}$ et al. (2009): Role for interleukin-6 in COPD-related pulmonary hypertension. Chest, 136(3): 678-687.

6. Rabe KF, Hurd S, Anzueto A, Barnes PJ, Buist SA, Calverley P, Zielinski J (2007): Global strategy for the diagnosis, management, and prevention of chronic obstructive pulmonary disease: GOLD executive summary. American Journal of Respiratory and Critical Care Medicine, 176(6): 532-555.

7. Fayngersh V, Drakopanagiotakis F, McCool FD, Klinger JR (2011): Pulmonary hypertension in a stable community-based COPD population. Lung, 189(5): 377.

8. Wright JL, Levy RD, Churg A (2005): Pulmonary hypertension in chronic obstructive pulmonary disease: current theories of pathogenesis and their implications for treatment.Thorax., 60(7): 605-609.

9. Kessler R, Faller M, Weitzenblum E, Chaouat A, Aykut A, DucolonÉ A, Oswald-Mammosser M (2001): Natural history of pulmonary hypertension in a series of 131 patients with chronic obstructive lung disease. American Journal of Respiratory and Critical Care Medicine, 164(2): 219224.

10. Schreier DA, Hacker TA, Hunter K, Eickoff J, Liu A, Song G, Chesler N (2014): Impact of increased hematocrit on right ventricular afterload in response to chronic hypoxia. Journal of applied physiology, 117(8): 833-839. 